\title{
What Makes Fractional CIO Engagements in SMEs Successful? - A Research Framework
}

\author{
Simon Kratzer \\ TU Dresden, Germany \\ simon.kratzer@mailbox.tu-dresden.de
}

\begin{abstract}
As information technology (IT) becomes more important for organizations, the necessity for strategic IT management and alignment grows. However, most small-to medium-sized enterprises (SMEs) do not have the resources or appeal to employ a full-time Chief Information Officer (CIO). Refraining from assigning such responsibilities can have severe consequences on an organization's performance. To address this gap, several individuals already follow the role of holding CIO positions at multiple SMEs, each with a fraction of their time. While the so-called "Fractional CIO" role is already creating value in practice, there is no research on Fractional CIO engagements. This paper develops a research framework for Fractional CIO engagement success based on interviews with 40 Fractional CIOs from 10 countries and existing literature. The components influencing success are the Fractional CIO, the client, their relationship, and the engagement setup. The paper contains implications for theory and practice and outlines detailed next steps.
\end{abstract}

\section{Introduction}

There is an increasing need for information systems and technology (IS/IT) adoption in organizations to stay competitive. This poses challenges to all types of organizations. Especially small- to medium-sized enterprises (SMEs) have difficulties in IS/IT adoption [1]. Although there is an increasing trend for IT use in SMEs [2-4], research suggests several reasons for its low adoption. Some suggest it is because they lack proper planning [5]; others argue that SMEs lack the resources, not only technical and financial but also managerial [2]. Caldeira and Ward [6] find that support and attitude of executives towards IS/IT adoption is an essential factor for success. Especially proper IT management and the presence of a capable Chief Information Officer (CIO) enable a positive influence of IS/IT on organizational performance $[6,7]$. However, most SMEs exhibit limited resources not allowing for a full-time CIO position. Instead, they rely on external support regarding their IT function or sometimes even have responsibility assigned to an executive with a different focus and even different background [8]. Failing to give responsibilities for strategic IT management and alignment to an experienced IT executive will result in not staying competitive, reduced performance, and eventually lost business value $[1,7$, 9-11].

To address this issue, an increasing number of SMEs started to employ CIOs part-time [12]. In academia, only a few sources provide information on this novel role $[13,14]$. Such CIOs are usually senior IT professionals with a profound experience as CIOs in different contexts and organizations. They serve multiple client organizations at the same time, each with a fraction of their time. This way, the SMEs get access to the experience and expertise they need at a fraction of the cost without making long-term commitments. Our interviews with forty individuals in such roles revealed that no consistent naming exists [14]. The most common terms are Virtual (16), Fractional (14), Interim (6), and Part-time (2) CIO. While Virtual and Interim are already existing terms for other roles $[15,16]$, a Parttime CIO could also just work part-time at only one organization. Hence, we use the term Fractional CIO. Such Fractional CIOs are usually self-employed; however, there are already partnerships and organizations bundling such services. Freeman Clarke is one of the leading organizations providing SMEs with Fractional CIOs, proving the model successful and relevant [17]. Since the role of the Fractional CIO is relatively new and has not found attention in research yet, little is known about what is needed to make such a Fractional CIO engagement successful. To close this gap, we propose the following research question:

(RQ) What factors contribute to the success of a Fractional CIO engagement?

Following an exploratory approach, this paper offers contributions to theory and practice. First, it develops a Fractional CIO engagement success framework, deriving potential influence factors from 
interviews with Fractional CIOs and existing literature. Second, to show how researchers may work with the framework, it outlines specific next steps for validation and further development of the proposed framework. Third, it helps raise awareness of the Fractional CIO role and provides practical advice for them and their clients.

The paper is structured as follows: Following the introduction, section 2 provides research background on related research areas. After a detailed description of the methodology, the following section presents the results, including descriptive statistics and the proposed research framework. Next, concrete next steps for further development of the research framework are outlined. The paper concludes by stating implications for theory and practice and pointing out limitations.

\section{Research background}

This paper develops a framework for Fractional $\mathrm{CIO}$ engagement success. Since the Fractional CIO role has not been studied yet, we look at adjacent research fields in this section. First, we look at the literature on fractional management in SMEs. Second, we analyze the vast body of existing literature on CIO and top management team (TMT) effectiveness. Third, we examine the research field of consulting engagement success.

\subsection{Fractional management in SMEs}

While several individuals and partnerships in practice already offer the service of a Fractional CIO, the role has not found much attention in research yet. However, there are a few press releases and papers on fractional, virtual, and interim management. We structure this subsection following Kratzer et al. [14].

Elder [18] describes fractional managers as individuals that are not consultants or part-timers but senior-level people with decades of experience and committed to the long-term success of their clients. Despite fulfilling the role of senior-level individuals, fractional managers only commit a fraction of their time to each client. This enables SMEs to get the experience and expertise they need, e.g., to establish IT security standards, at a fraction of the cost of a full-time manager [18]. Kratzer et al. [14] are the first to conceptualize the role of the Fractional CIO in SMEs and define the role as " a highly experienced and competent individual that acts in the capacity of a CIO, but only part-time, depending on the clients' needs. The Fractional CIO serves multiple clients at the same time and often has the authority and responsibility of a full-time $\mathrm{CIO}$ and (in-)directly manages each of his/her clients' IT staff and suppliers." Definitions and descriptions of the role in practice are similar $[12,17]$.
Related fields of fractional management are virtual and interim management. Although these terms are often intermingled, there are certain distinctive features to each concept. The most established field is interim management, which has been utilized for decades already [15]. "Interim-Management is the temporary transfer of external leadership personnel into an enterprise with the objective to perform selected managerial tasks" [15] (p. 514). Compared to fractional management, however, although interim management is temporary, it implements a full-time position. Hence, it provides organizations with temporary full access to the experience and expertise they need without making any long-term commitments [19]. On the other hand, a virtual manager is a full-time employee working remotely [16]. Smith and Sinclair [16] (p. 8) define a "virtual manager as someone who manages people, works at a separate geographical location from their team for at least some of the time, and communicates with their people other than by regular face-to-face contact, for example by e-mail or phone."

While both, interim and virtual managers, offer advantages in terms of flexibility, in the short term, the cost for such roles is most likely not lower than for a full-time manager. Especially SMEs, however, often do not have the resources to access the experience and expertise they need and could, therefore, highly profit from the concept of fractional management. For larger organizations, on the other hand, a fractional manager would most likely not be sufficient to fulfil the organizations' needs. Hence, we argue that fractional management is primarily relevant for SMEs.

\subsection{CIO and TMT effectiveness}

The effects of executives on organizational performance drew a lot of attention from researchers [20-22]. This topic is not just highly relevant for larger organizations but also for SMEs [23-25]. Although the Fractional CIO is a part-time position, it aims to fill the role of an executive. Therefore, we build on the literature on CIO and TMT effectiveness to substantiate initial hypotheses for the effectiveness of the Fractional CIO. To ensure we do not miss relevant work from CIO literature, we conducted a thorough literature review regarding the role of the $\mathrm{CIO}$ in a previous study [26].

The influence of CIOs on organizational performance is heavily discussed in IS research [27-31]. Many of those studies find that the CIO is indeed essential for organizational performance. Smaltz et al. [28] analyze the antecedents of CIO role effectiveness in organizations and find that the CIO's political savvy, communicative ability, strategic business knowledge, and strategic IT knowledge make the role effective. Hütter and Riedl [31] conduct a comprehensive 
literature review regarding $\mathrm{CIO}$ role effectiveness and the factors that influence it. On the highest level, they find that the factors $C I O$ personal competence, CIO hierarchical position, management environment, and IT infrastructure influence CIO role effectiveness. In this case, CIO personal competence includes technical competence, IT management competence, business competence, communication competence, and political competence.

Since Fractional CIOs act as "normal" CIOs but just with a fraction of their time, the competencies and skills of both roles should be similar. Therefore, we presume that the personal competencies and skills are similarly important to Fractional CIO engagement success as they are for the success of a CIO.

Besides CIO effectiveness, there is also much research attention on TMT effectiveness. Upper Echelons Theory, one of the most influential perspectives in management research, states that an executive's experiences, values, and personality influence organizational outcomes [32]. While the theory is still widely applied, there is criticism of how research utilizes upper echelons theory [33]. In the past two decades, there has been an increased focus on not only the executives' characteristics but rather the entire top management team's composition and processes that influence organizational outcomes [34-36]. As a result, several studies explored the concept of behavioral integration, which includes the TMTs level of collaboration, information exchange, and joint decision making [37, 38].

Carmeli [39] looks at organizations in the service sector and finds that TMT behavioral integration is positively linked to human resources and economic performance. Lubatkin et al. [25] find support for their hypothesis that TMT behavioral integration is essential for attaining ambidexterity and, ultimately, firm performance in SMEs. Jahanshahi and Brem [24] surveyed TMTs in Iranian SMEs and found a strong link between a behaviorally integrated TMT and its innovativeness. However, increased collaboration and interaction between TMT members do not always seem beneficial to the team or firm performance. Barrick et al. [40] show that TMTs with high interdependence achieve higher firm performance in case they exhibit more cohesiveness and communication. TMTs with low interdependence, on the other hand, achieve higher firm performance in case they do not communicate and cohere as much.

Overall, the concept of TMT behavioral integration suggests that the engagement setup and the relationship between a Fractional CIO and its clients are crucial for engagement success.

\subsection{Consulting engagement success}

Consulting engagement success is a major research stream in consulting research [41]. Studies are concerned with consulting engagement success [42] and how to measure it [43]. Furthermore, studies analyzed the factors that influence the success of consulting engagements [44, 45].

Whether a consulting engagement is seen as success depends on which involved party is asked, since both client and consultant expectations need to be met [42]. McLachlin [42] (p. 149) defines an engagement as successful "if the client is satisfied that the consultant has met expectations (by improving one or more of client performance, client capabilities, or organisational culture, without making any category worse) - whether or not a core need has been addressed - and the consultant is satisfied that his/her reputation has been enhanced, with expectations of future revenue streams - whether or not any immediate income has been received." Gable [43] proposes a measurement model for assessing engagement success when hiring external consultants. The study identifies six dimensions of engagement success: consultant's recommendation, client learning, and consultant performance. Bronnenmayer et al. [46] find that from the consultants' viewpoint, the factors intensity of collaboration, common vision, consultant expertise, and top management support significantly influence perceived engagement success.

Jang and Lee [45] develop a framework for consulting success with the dimensions competence of consultants (e.g., expert, manager, researcher), consultation mode (e.g., clearly defined goals, clients' participation), and client organizational characteristics (e.g., top management support, commitment of client team members). McLachlin [44], on the other hand, proposes six universal factors that influence engagement success: consultant integrity, client involvement and readiness to change, agreement concerning requirements and expectations, client control of the engagement, consultant competence, and good fit between consultancy and client.

Since the Fractional CIO is, like a consultant, externally employed, we infer that similar factors influence engagement success. Besides already known factors like expertise, collaboration, and top management support, the client seems to be a vital part of the success of a Fractional CIO engagement.

\section{Methodology}

Since the role of the Fractional CIO did not receive much attention in research yet, this paper works towards theory building by following an exploratory approach 
[47]. Ridder [48] outlines that, in contrast to developing theory, building theory is the starting point of theorizing, with no available theory yet which explains the phenomenon. To develop initial hypotheses on the factors that influence Fractional CIO engagement success, we use data gathered through semi-structured interviews $[49,50]$ in the context of a larger research project on the Fractional CIO [14]. We compare and complement these insights with existing literature on related topics, like CIO and TMT effectiveness and consulting engagement success. The data collection process consisted of five steps which the following paragraphs describe [14].

First, we developed a set of questions using existing literature in research and practice and our own experiences. We structured the catalog of questions along the categories background of the interviewee, reasons for organizations to hire a Fractional CIO, setup and execution of the role, key requirements of effective Fractional CIOs, and success factors and challenges of Fractional CIO engagements. For this study, especially the last three question categories are important.

Second, we approached potential interviewees through personal connections as well as the professional network LinkedIn. The search terms we used were Virtual CIO (292), vCIO (320), Part-time CIO (295), and Fractional CIO (295), and we searched in October 2020. After excluding irrelevant and duplicated results, we contacted a total of 500 individuals via LinkedIn. Additionally, we contacted 15 individuals via personal connections. If the individuals were willing to participate in the study, we shared additional information and scheduled an online meeting.

Third, we conducted semi-structured interviews with individuals in a Fractional CIO role between November 17, 2020, and April 7, 2021 [51]. Upon approval of the interview participant, we recorded each interview and transcribed it carefully afterwards. After each interview, we adjusted and refined the question catalog if needed. After a total of 40 interviews with, on average, 40 minutes each, we did not find any new insights anymore and, therefore, stopped scheduling further meetings.

Fourth, using the software MAXQDA 2020 [52], we conducted a thorough coding of the interview transcripts following Saldaña [53]. We iteratively assessed codes during the coding process and, if needed, refined, re-labeled, re-assigned, or dropped them. A second researcher reviewed the codes, and we resolved ambiguous codes in a discussion. Of the more than 30 coding methods proposed by Saldaña [53], we used similar coding methods to the ones used for grounded theory. We started with the elemental method "in Vivo Coding" to attune ourselves to the interviewees' language and also used exploratory, grammatical, eclectic, and axial coding methods. Wiesche et al. [54] (p. 697) argue that even if a study does not strictly follow the grounded theory methodology, it can still "make a major contribution by developing pretheoretical models and rich descriptions of new phenomena."

Fifth, based on the coding results, we quantitatively and qualitatively evaluated the following topics of interest: setup and execution of the Fractional CIO role, key requirements of effective Fractional CIOs, and success factors and challenges of Fractional $\mathrm{CIO}$ engagements. Within these topics, we chose all factors that were at least mentioned by $20 \%$ of interviewees. Using frameworks from existing literature, we validated, complemented, and grouped the factors to develop our research framework.

\section{Proposed research framework}

In this section, we display the results. First, we present descriptive statistics on the interviewees. Second, we introduce the research framework for Fractional $\mathrm{CIO}$ engagement success and discuss each factor in detail.

\subsection{Descriptive statistics}

Overall, we conducted 40 interviews with individuals in a Fractional CIO role (Table 1) [14]. Out of 40 interviewees, only one was female. More than half are living in North America (16 United States of America (US), five Canada CA)), seven are from New Zealand (NZ), six from the United Kingdom (UK), and six from other countries such as Australia (AU), Germany (DE), India (IN), Ireland (IE), South Africa (ZA), and Spain (ES).

Table 1. Descriptive statistics [14]

\begin{tabular}{|l|l|l|r|r|}
\hline $\begin{array}{l}\text { Inter- } \\
\text { viewee }\end{array}$ & $\begin{array}{l}\text { Coun- } \\
\text { try }\end{array}$ & $\begin{array}{l}\text { Current } \\
\text { number } \\
\text { of clients } \\
\text { IT experience } \\
\text { (in years) }\end{array}$ & $\begin{array}{l}\text { Professional } \\
\text { ence in } \\
\text { role (in } \\
\text { years) }\end{array}$ \\
\hline CIO\#01 & US & 2 & $>30$ & $<5$ \\
\hline CIO\#02 & NZ & 3 & $>30$ & $10-20$ \\
\hline CIO\#03 & CA & n/a & $>30$ & $<5$ \\
\hline CIO\#04 & ZA & n/a & $20-30$ & $<5$ \\
\hline CIO\#05 & IE & 5 & $10-20$ & $<5$ \\
\hline CIO\#06 & IN & 3 & $>30$ & $5-10$ \\
\hline CIO\#07 & US & 2 & $20-30$ & $<5$ \\
\hline CIO\#08 & NZ & 3 & $>30$ & $5-10$ \\
\hline CIO\#09 & NZ & 4 & $20-30$ & $<5$ \\
\hline CIO\#10 & NZ & 4 & $>30$ & $<5$ \\
\hline CIO\#11 & CA & 3 & $20-30$ & $<5$ \\
\hline
\end{tabular}




\begin{tabular}{|l|l|l|r|r|}
\hline CIO\#12 & US & 4 & $>30$ & $>20$ \\
\hline CIO\#13 & US & 3 & $>30$ & $>20$ \\
\hline CIO\#14 & CA & n/a & $20-30$ & $>20$ \\
\hline CIO\#15 & US & n/a & $<10$ & $<5$ \\
\hline CIO\#16 & NZ & 6 & $10-20$ & $5-10$ \\
\hline CIO\#17 & US & 3 & $>30$ & $<5$ \\
\hline CIO\#18 & NZ & 3 & $>30$ & $<5$ \\
\hline CIO\#19 & AU & 3 & $20-30$ & $<5$ \\
\hline CIO\#20 & NZ & n/a & $20-30$ & $<5$ \\
\hline CIO\#21 & UK & 2 & $>30$ & $<5$ \\
\hline CIO\#22 & UK & 5 & $>30$ & $<5$ \\
\hline CIO\#23 & CA & n/a & $20-30$ & $5-10$ \\
\hline CIO\#24 & UK & n/a & $>30$ & $5-10$ \\
\hline CIO\#25 & US & 5 & $20-30$ & $5-10$ \\
\hline CIO\#26 & US & n/a & $>30$ & $5-10$ \\
\hline CIO\#27 & UK & 2 & $>30$ & $<5$ \\
\hline CIO\#28 & US & 5 & $>30$ & $10-20$ \\
\hline CIO\#29 & UK & 3 & $>30$ & $5-10$ \\
\hline CIO\#30 & US & 2 & $20-30$ & $<5$ \\
\hline CIO\#31 & US & 4 & $>30$ & $5-10$ \\
\hline CIO\#32 & US & 4 & $20-30$ & $<5$ \\
\hline CIO\#33 & UK & 3 & $20-30$ & $<5$ \\
\hline CIO\#34 & US & 2 & $20-30$ & $<5$ \\
\hline CIO\#35 & US & 6 & $>30$ & $<5$ \\
\hline CIO\#36 & US & 3 & $20-30$ & $10-20$ \\
\hline CIO\#37 & US & n/a & $20-30$ & $5-10$ \\
\hline CIO\#38 & ES & 3 & $20-30$ & $<5$ \\
\hline CIO\#39 & CA & 3 & $10-20$ & $5-10$ \\
\hline CIO\#40 & DE & 2 & $20-30$ & $<5$ \\
\hline & & &
\end{tabular}

The interviewees' current number of clients ranges from two to six. Most interviewees have more than 20 years of experience, 19 with $>30$ years of experience, and 17 with 20 to 30 years of experience. With the experience in the role, however, it is the other way round. More than half of the interviewees (23) are less than five years in the role of a Fractional CIO. Another eleven are in the role for 5 to 10 years. Only six interviewees are in the role for more than 10 years already. All those individuals started without knowing anyone else in such a role. For some, it began as a consulting role after being a $\mathrm{CIO}$; others called their service directly CIO On-demand or Virtual CIO.

\subsection{Factors for Fractional CIO engagement success}

Combining insights from the 40 interviews with Fractional CIOs and existing literature, we developed a research framework for Fractional CIO engagement success (Figure 1). We identified four components of a Fractional CIO engagement by counting the number of interviewees that mentioned a factor for engagement

success and by then validating, complementing, and grouping them through exiting literature. There are the two parties, the Fractional $C I O$ and the client, their relationship, and the engagement setup. Each of these components includes several factors that influence engagement success. In the following, we present each component and its factors in more detail.

4.2.1. Fractional CIO. We identified six personal competencies and characteristics of Fractional CIOs that influence engagement success. The majority of Fractional CIOs (25) agree that the factor experience in IT and CIO positions is critical (CIO\#03): "It's the experience of being a CIO that helps those engagements become successful."

Further, we found strong evidence for business competence (14), knowledge in IT and current trends (14), and translator between business and IT (16) as requirements for successful Fractional CIOs. Business competence helps in the more strategic tasks of a CIO (CIO\#16): "You've got to [...] be able to take the IT hat off. Any true CIO role doesn't think technology. [...] It's recognizing that you need to keep yourself elevated, and you need to think business and strategy." Technical competence and knowledge of current trends, on the other hand, help to get credibility from employees as well as in negotiating with vendors (CIO\#31): "I think what makes a good CIO in general, whether virtual or not, is the ability to understand technology enough so that you can dive down, if not totally, at least to a level where you can have intelligent conversations with the staff and vendors. "Further, CIO\#08 emphasizes that "it is [important] to be on top of all the different technologies or information and trends that are relevant to the client." To be an effective Fractional CIO, one needs to act as a translator between business units and IT. Hence, a combination of the competencies is required (CIO\#04): "Working with both the business side of things with their requirements [...] in "business terminology" and then working with software developers, understanding their typical processes and terminology, [...] to kind of act as that translation layer between the two is a key requirement."

Another skill that repeatedly surfaced during the interviews was integrity (13). In contrast to consultants, Fractional CIOs are more committed to the long-term success of their clients and do not depend as much on follow-up work [13]. However, Fractional CIOs could also profit from extending problems instead of solving them or looking for follow-up work to ensure their project pipeline is filled. Yet, most Fractional CIOs claimed that their integrity is a unique selling point of their business model (CIO\#35): "In the ones where there's a definitive end goal, I always try to make them independent of me [...]. Yes, that complicates sales for 
me, but ethically, I can't justify doing my business any other way. [...] It's very easy to start to think of the client as a revenue generation unit instead of somebody that needs help. Staying true to my clients and not chasing the revenue is very important." have to have executive sponsorship. Someone, either an owner or an investor, or an existing executive, [who] wants you there and wants you to be successful. I think that's the most important thing." Additionally, buy-in from the organization is needed to facilitate change

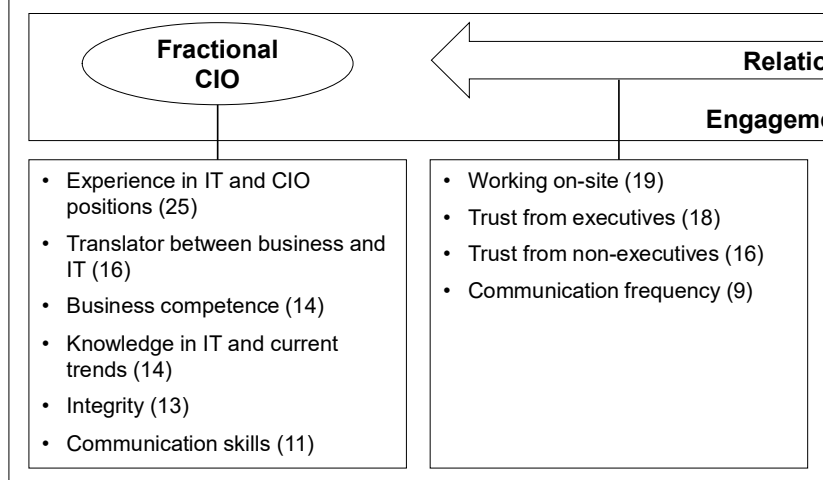

Engagement success

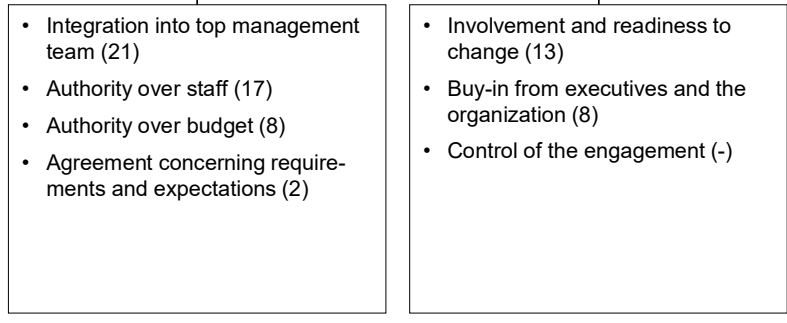

(x) - Number of interviewees mentioning the factor

Figure 1. Research framework for Fractional $\mathrm{CIO}$ engagement success

The last factor for engagement success within the Fractional CIO's competencies and characteristics we identified was communication skills (11). Fractional CIOs often find themselves in delicate situations, such as being in charge while not being the direct supervisor of the staff (CIO\#08): "They have to be collaborative and a good communicator. They can't come in and say I know everything about everything. Just let me sort you all out and push people around. That's not the right way. So, they can't be the know-it-all. They have to actually listen and talk with people." Further, they must be able to voice their concerns in an effective way to the organization's executives (CIO\#28): "You have to be a person that's able to talk to $C F O, C E O$, presidents, chief executives and be able to voice your concerns for the company without backing down."

Looking into the literature on CIO effectiveness and consulting engagement success, we find support for all identified competencies and characteristics. This is not surprising since the Fractional CIO role is between a full-time CIO and a consultant. While integrity is identified by McLachlin [44] as a factor for consulting engagement success, all remaining factors are discussed in both research streams for effectiveness and success $[28,31,44,46]$.

4.2.2. Client. Besides the Fractional CIO, the client organization also influences the success of an engagement. Through the interviews, we identified the two factors involvement and readiness to change (13) and buy-in from executives and the organization (8). Without having the buy-in from executives, the Fractional CIO is unlikely to succeed (CIO\#13): "You
(CIO\#04): "There also needs to be buy-in from the organization so that they will actually listen to me and take what I'm saying."

Furthermore, the client needs to be involved in the engagement (CIO\#15): "They have to respond quickly. If they are not engaged with you, you're not going to be aware of what's happening. And that's going to affect your judgment and your recommendation. So, you need active client participation." $\mathrm{CIO \# 22}$ stresses that the client needs to be open and ready to change to ensure engagement success: "They've got to be open to change. [...] They have to be recognizing that there's something that has to change, and that's probably the key thing that you need from the client and the executive teams in that position."

Both factors, involvement and readiness to change as well as buy-in from executives and the organization are supported by consulting engagement success literature [44-46]. As we did not interview clients of Fractional CIOs in this first round of interviews, we might have missed factors on the clients' side that influence engagement success. Therefore, we looked into the literature and found that McLachlin [44] also considers client control of the engagement a universal factor influencing engagement success. Consequently, we include the factor control of the engagement in our research framework.

4.2.3. Relationship. The relationship between a Fractional $\mathrm{CIO}$ and the client constitutes a key variable for the success of an engagement (CIO\#12): "Any CIO that comes from the technical side has, in general, more difficulty in building those relationships, but those 
relationships are absolutely critical to my successful contracts."

Several factors are important to build and sustain a fruitful relationship. One of the most frequently mentioned factors across all interviews was to gain trust from the executives (18). CIO\#32 sees trust as a prerequisite for success: "I feel like I'm selling trust more than anything else. Like sure, the expertise is part of it and all that, but my kind of work is only successful if the customer feels like I'm making decisions in their best interest." CIO\# 28 confirms this statement: "The best clients I've been a virtual CIO for are the ones where the trust factor is at its highest. The line between employee and consultant is gone. Right. And those are the most successful engagements there are."

To effectively deliver towards the agreed-upon goals, the Fractional CIO additionally needs the trust from non-executives (16) (CIO\#10): "I think number one is the ability to build effective working relationships with the non-IT executives." This is especially true in case there are cultural problems at the client organization, or the Fractional CIO is seen as an external party that might be a threat to some of the internal employees (CIO\#13): "Once you get a little bit of trust, that they see you're not there to just totally ruin their lives, they'll tell you things they would never tell their manager or boss. They'll tell you in hopes that you'll be able to do something about it."

Another factor influencing an engagement's success is how often the Fractional CIO is physically working on-site and has facetime with the client (19). However, there are different opinions among the interviewed Fractional CIOs on it. Some see it as a benefit to be on-site (CIO\#24): "I prefer to be at the client because, as I said earlier, you have to be ingrained in the business. You have to be involved in the fabric. And it's quite hard to do that when you're working from home." Other Fractional CIOs emphasize the advantages of remote work (CIO\#13): "Most of it is virtual, even before Covid. But with Covid, these kinds of meetings are even easier, because you don't have to commute. And so that's great."

Related to that is the communication frequency (9) between the Fractional CIO and members of the client team. While the Fractional CIO might only allocate one or two days to a client, this does not mean that there is no communication allowed in between those days. On the contrary, several interviewees emphasize the importance of checking in with their clients regularly to ensure not missing out on information (CIO\#21): "Because you are not in the room mentally with that organization 100 percent of the time, you can miss things. [...] So, for instance, as you're approaching a goal or a phased deliverable, you need to invest a bit more time to work with the team to check-in, [...] taking the pulse of what the issues are and then moving past them."

Overall, we identified the four factors working onsite, trust from executives, trust from non-executives, and communication frequency within the relationship between the Fractional $\mathrm{CIO}$ and client that influence Fractional CIO engagement success. We were able to validate all factors through existing literature. Trust and close collaboration are supported by the concept of behavioral integration in the context of TMT effectiveness [37, 38]. Similarly, all factors applied to the consultant-client relationship find support in consulting engagement success literature $[46,55]$.

4.2.4. Engagement setup. The last component within the Fractional CIO engagement success framework, engagement setup, comprises four factors. As the Fractional CIO needs to act in the capacity of a CIO, it is vital to integrate the role into the top management team (21) (CIO\#01): "I should be treated as a CIO in the sense that I'm one of the key executives of the company, and I get access to the CEO or executive director, and I hear about leadership calls."

In line with this integration, the Fractional CIO requires at least some authority over the existing staff (17) (CIO\#08): "I have the authority of basically managing their work, so assigning them tasks. Determining what's good, or evaluating their performance, approving timesheets, or annual leave or any of that sort of stuff that's always left with a staff member." Some Fractional CIOs have full authority over the IT staff (CIO\#12): "In most cases I hire them. So, I'll hire IT people to fill those roles. And so, because I hire them, I have the power to fire them. That's heavyhanded. I'm managing them, they expect to take instructions from me." In rare cases, the IT staff does not even know that the CIO is fractional (CIO\#31): "Typically, nobody knows that I'm not a full-time employee. So yes, I have staff, and I always have full hiring and firing capabilities. The same as a real CIO would have."

Further, to not be held up by more minor approvals, authority over a certain budget is required (8) (CIO\#18): "And you really want at least a limited budget. The virtual CIO. So, you're not having to go back to senior management for things like saying, "We need a new software package for this area.",

The last factor is agreement concerning requirements and expectations of the engagement (2). Although the number of interviewees that mentioned this factor is below $20 \%$, we included it in the framework as it has a strong foundation in literature [44]. It is crucial to continuously monitor those requirements and expectations throughout the engagement (CIO\#36): "Managing scope with my 
clients is a major challenge. Which is a double-edged sword. It's really neat that they want me to do more things, but they just keep piling things on the plate and expecting everything that they've already talked about to get done, and here are all the new things."

The factor agreement concerning requirements and expectations is also the only one of these four factors we find support for in consulting engagement success literature [44]. The fact that the factors integration into top management team, authority over staff, and authority over budget are not discussed in consulting literature is a new finding that fits the Fractional CIO's special notion. While consultants are external employees, it is not always that clear for a Fractional CIO (see the quote of CIO\#31 above). To act as the CIO of an organization, the Fractional CIO needs to be integrated into the TMT and needs at least some authority. Therefore, the component engagement setup needs to be extended to account for fractional managers.

\section{Suggested framework use and next steps}

The research framework for Fractional CIO engagement success serves as a basis for numerous possibilities for further research. Both quantitative and qualitative studies would be suitable to build on the framework and to develop it further. To conduct a quantitative study, however, the framework would first need to be further developed into a causal model and further embedded in existing theory. The current framework can serve as a frame of reference to this end. However, as the research field of the Fractional CIO is new, exploratory qualitative studies are presumably more suited to understand the novel concept.

Therefore, we will conduct a Q-sort study with individuals in a Fractional CIO engagement as a next step. The goal is to validate the proposed research framework, determine the relative importance of factors, and identify different viewpoints on engagement success.

Q-methodology has been studied for decades and is heavily applied across various research fields, including psychology, social sciences, and marketing [56, 57]. The method, Q-sorting, aims to identify individuals' subjective viewpoints in a rigorous quantitative way [58]. Participants are required to sort a set of statements according to their significance following a forced distribution. Afterwards, Q-factor analyses are applied to identify the relative importance of each factor and different types of respondents.

The methodology is also common in IS research [59-61]. Tractinsky and Jarvenpaa [61] use Q-sorting to analyze different perspectives of IT project managers regarding information system design decisions. Kendall et al. [59] use Q-sorting to identify various organizational subcultures and their user satisfaction with decision support systems. To ensure proper application of this methodology, we will follow the recommendation proposed by Thomas and Watson [60], who offer clear guidance on applying the Q-sort methodology.

In this analysis, Q-sorting offers several advantages over other qualitative methods. The method is wellsuited for exploratory research, its theory is welldeveloped, and there is extensive guidance. It delivers meaningful results even with small sample sizes, and a random selection of participants is not required [60]. Therefore, we aim to analyze the relative importance of all factors for Fractional CIO engagement success. Further, we will investigate the ranking of factors and their relative importance from different viewpoints, e.g., Fractional CIO vs. client.

\section{Conclusion}

This paper proposes a research framework for Fractional CIO engagement success and outlines specific next steps for further research. We find that four components influence the success of a Fractional CIO engagement: The Fractional CIO, the client, their relationship, and the engagement setup. For each component, we outline several factors derived from interviews with 40 Fractional CIOs and existing literature. We find that the component engagement setup has not seen much attention in research in general. Hence, we propose an extension in the case of Fractional CIO engagements. With this framework, we developed a common ground for future research to investigate further what factors influence engagement success.

This paper also has implications for practice. While the role of the Fractional CIO can benefit many SMEs around the world, its adoption is still low. On the one hand, this study can help to raise awareness of the existence of the role. On the other hand, it provides practical advice for Fractional CIOs and SMEs on what to focus to make the engagement a success.

This study has limitations. First, while a Fractional CIO engagement involves two parties, a Fractional CIO and a client organization, we limited the interviews to Fractional CIOs to develop the research framework. Hence, we are potentially missing a perspective that could deliver more insights into the factors influencing success. However, we do not claim that the framework is comprehensive; it is an initial result that needs further refinement. In a follow-up study, we plan on analyzing the matter from both sides to validate and further refine the framework. Second, we ignored assembling a representative sample due to the limited number of individuals in the novel Fractional CIO role. When analyzing the results, we also did not account for 
regional differences. Since the role is evolving independently in different world areas, regional peculiarities might offer interesting insights.

\section{References}

[1] Nguyen, T.H., M. Newby, and M.J. Macaulay, "Information Technology Adoption in Small Business: Confirmation of a Proposed Framework", Journal of Small Business Management, 53(1), 2015, pp. 207-227.

[2] Bhagwat, R. and M.K. Sharma, "Information System Architecture: A Framework for a Cluster of Small- and Medium-Sized Enterprises (SMEs)", Production Planning \& Control, 18(4), 2007, pp. 283-296.

[3] Taylor, P., "The Importance of Information and Communication Technologies (ICTs): An Integration of the Extant Literature on ICT Adoption in Small and Medium Enterprises", International Journal of Economics, Commerce and Management, 3(5), 2015, pp. 274-295.

[4] Bi, R., R.M. Davison, and K.X. Smyrnios, "IT and Fast Growth Small-to-Medium Enterprise Performance: An Empirical Study in Australia", Australasian Journal of Information Systems, 19, 2015, pp. S247-S266.

[5] Levy, M., P. Powell, and P.W. Yetton, "SMEs: Aligning IS and the Strategic Context", Journal of Information Technology, 16(3), 2001, pp. 133-144.

[6] Caldeira, M. and J. Ward, "Understanding the Successful Adoption and Use of IS/IT in SMEs: An Explanation From Portuguese Manufacturing Industries", Information Systems Journal, 12(2), 2002, pp. 121-152.

[7] Pigni, F., A. Ravarini, M. Tagliavini, and J. Moro, "Using ICT to Improve SMEs Performance: Does the CIO Matter?", in Proceedings of the 6th World Multiconference on Systematics, Cybernetics and Informatics, SCI, Orlando, Florida, USA, 14-18 July. 2002.

[8] Cragg, P., A. Mills, and T. Suraweera, "The Influence of IT Management Sophistication and IT Support on IT Success in Small and Medium-Sized Enterprises", Journal of Small Business Management, 51(4), 2013, pp. 617-636.

[9] Smith, H.A., J.D. McKeen, and S. Singh, "Developing Information Technology Strategy for Business Value", Journal of Information Technology Management, XVIII(1), 2007, pp. 49-58.

[10] Ross, J.W. and P. Weill, "Six IT Decisions Your IT People Shouldn't Make", Harvard Business Review, 80(11), 2002, 84-91.

[11] Kim, M.-K. and K. Jee, "Factors Influencing Strategic Use of Information Technology and Its Impact on Business Performance of SMEs", ETRI Journal, 29(4), 2007, pp. 497-506.

[12] Moise, D., "Part-Time CIOs Can Help With Digital Transformations", Forbes, 03.02.2021, available at: www.forbes.com/sites/forbestechcouncil/2021/02/03/pa rt-time-cios-can-help-with-digital-transformations.

[13] Elder, D., "Fractional Management vs. Part-Timers, Consultants", Business in Savannah, 2011, available at:
bgaccelerators.com/newspapercolumns/FractionalManagers-vs-part-timers-consultants-part-4-of-4.PDF.

[14] Kratzer, S., A. Drechsler, M. Westner, and S. Strahringer, "The Fractional CIO in SMEs: Conceptualization and Research Agenda", submitted to journal, 2021.

[15] Bruns, J. and R. Kabst, "Interim-Management: A Paradox for Leadership Research?", Management Revue, 16(4), 2005, pp. 512-524.

[16] Smith, A. and A. Sinclair, What Makes an Excellent Virtual Manager?, Roffey Park, Horsham, 2003.

[17] Freeman and Clarke Limited, "Home page - Freeman Clarke", accessed on: 26.07.2021, available at: www.freemanclarke.co.uk.

[18] Elder, D., "How a Fractional Manager Might Benefit Your Business", Business in Savannah, 2011, available at: bgaccelerators.com/newspapercolumns/FractionalManagers-How-they-might-benefit-your-business-part2-of-4.PDF.

[19] Inkson, K., A. Heising, and D.M. Rousseau, "The Interim Manager: Prototype of the 21st-Century Worker?", Human Relations, 54(3), 2001, pp. 259-284.

[20] Mackey, A., "The Effect of CEOs on Firm Performance", Strategic Management Journal, 29(12), 2008, pp. 13571367.

[21] Banker, R.D., N. Hu, P.A. Pavlou, and J. Luftman, "CIO Reporting Structure, Strategic Positioning, and Firm Performance", MIS Quarterly, 35(2), 2011, pp. 487-504.

[22] Khallaf, A. and T. Skantz, "Does Long Term Performance Improve Following the Appointment of a CIO?", International Journal of Accounting Information Systems, 12(1), 2011, pp. 57-78.

[23] Escribá-Esteve, A., L. Sánchez-Peinado, and E. SánchezPeinado, "The Influence of Top Management Teams in the Strategic Orientation and Performance of Small and Medium-sized Enterprises", British Journal of Management, 20(4), 2009, pp. 581-597.

[24] Jahanshahi, A.A. and A. Brem, "Sustainability in SMEs: Top Management Teams Behavioral Integration as Source of Innovativeness", Sustainability, 9(10), 2017, p. 1899.

[25] Lubatkin, M.H., Z. Simsek, Y. Ling, and J.F. Veiga, "Ambidexterity and Performance in Small-to MediumSized Firms: The Pivotal Role of Top Management Team Behavioral Integration", Journal of Management, 32(5), 2006, pp. 646-672.

[26] Kratzer, S., M. Westner, and S. Strahringer, "Four Decades of Chief Information Officer Research: A Literature Review and Research Agenda Based on Main Path Analysis", submitted to journal, 2021.

[27] Johnson, A.M. and A.L. Lederer, "CEO/CIO Mutual Understanding, Strategic Alignment, and the Contribution of IS to the Organization", Information \& Management, 47(3), 2010, pp. 138-149.

[28] Smaltz, D.H., V. Sambamurthy, and R. Agarwal, "The Antecedents of CIO Role Effectiveness in Organizations: An Empirical Study in the Healthcare Sector", IEEE Transactions on Engineering Management, 53(2), 2006, pp. 207-222.

[29] Armstrong, C.P. and V. Sambamurthy, "Information Technology Assimilation in Firms: The Influence of 
Senior Leadership and IT Infrastructures", Information Systems Research, 10(4), 1999, pp. 304-327.

[30] Karimi, J., Y.P. Gupta, and T.M. Somers, "The Congruence between a Firm's Competitive Strategy and Information Technology Leader's Rank and Role", Journal of Management Information Systems, 13(1), 1996, pp. 63-88.

[31] Hütter, A. and R. Riedl, "Chief Information Officer Role Effectiveness: Literature Review and Implications for Research and Practice", in Chief Information Officer Role Effectiveness, A. Hütter and R. Riedl, Editors. 2017. Springer International Publishing: Cham.

[32] Hambrick, D.C. and P.A. Mason, "Upper Echelons: The Organization as a Reflection of Its Top Managers", Academy of Management Review, 9(2), 1984, pp. 193206.

[33] Neely, B.H., J.B. Lovelace, A.P. Cowen, and N.J. Hiller, "Metacritiques of Upper Echelons Theory: Verdicts and Recommendations for Future Research", Journal of Management, 46(6), 2020, pp. 1029-1062.

[34] Hambrick, D.C., "Upper Echelons Theory: An Update", Academy of Management Review, 32(2), 2007, pp. 334 343.

[35] Simons, T., L.H. Pelled, and K.A. Smith, "Making Use of Difference: Diversity, Debate, and Decision Comprehensiveness in Top Management Teams", Academy of Management Journal, 42(6), 1999, pp. 662673.

[36] Carpenter, M.A., M.A. Geletkanycz, and W.G. Sanders, "Upper Echelons Research Revisited: Antecedents, Elements, and Consequences of Top Management Team Composition", Journal of Management, 30(6), 2004, pp. 749-778.

[37] Hambrick, D.C., Top Management Groups: A Conceptual Integration and Reconsideration of the "Team" Label: In B. M. Staw \& L. L. Cummings (Eds.), Research in Organizational Behavior, Vol. 16: 171-214, JAI Press, Greenwich, CT, 1994.

[38] Simsek, Z., J.F. Veiga, M.H. Lubatkin, and R.N. Dino, "Modeling the Multilevel Determinants of Top Management Team Behavioral Integration", Academy of Management Journal, 48(1), 2005, pp. 69-84.

[39] Carmeli, A., "Top Management Team Behavioral Integration and the Performance of Service Organizations", Group \& Organization Management, 33(6), 2008, pp. 712-735.

[40] Barrick, M.R., B.H. Bradley, A.L. Kristof-Brown, and A.E. Colbert, "The Moderating Role of Top Management Team Interdependence: Implications for Real Teams and Working Groups", Academy of Management Journal, 50(3), 2007, pp. 544-557.

[41] Cerruti, C., E. Tavoletti, and C. Grieco, "Management Consulting: A Review of Fifty Years of Scholarly Research", Management Research Review, 42(8), 2019, pp. 902-925.

[42] McLachlin, R., "Service Quality in Consulting: What Is Engagement Success?", Managing Service Quality: An International Journal, 10(3), 2000, pp. 141-150.

[43] Gable, G.G., "A Multidimensional Model of Client Success When Engaging External Consultants", Management Science, 42(8), 1996, pp. 1175-1198.
[44] McLachlin, R.D., "Factors for Consulting Engagement Success", Management Decision, 37(5), 1999, pp. 394404.

[45] Jang, Y. and J. Lee, "Factors Influencing the Success of Management Consulting Projects", International Journal of Project Management, 16(2), 1998, pp. 67-72.

[46] Bronnenmayer, M., B.W. Wirtz, and V. Göttel, "Determinants of Perceived Success in Management Consulting", Management Research Review, 39(6), 2016, pp. 706-738.

[47] Hassan, N.R., L. Mathiassen, and P.B. Lowry, "The Process of Information Systems Theorizing as a Discursive Practice", Journal of Information Technology, 34(3), 2019, pp. 198-220.

[48] Ridder, H.-G., "The Theory Contribution of Case Study Research Designs", Business Research, 10(2), 2017, pp. 281-305.

[49] Eisenhardt, K.M., "Building Theories From Case Study Research", Academy of Management Review, 14(4), 1989 , pp. 532-550.

[50] Yin, R.K., Case Study Research: Design and Methods, 5th edn., SAGE Publications, Thousand Oaks, CA, 2013.

[51] Myers, M.D. and M. Newman, "The Qualitative Interview in IS Research: Examining the Craft", Information and Organization, 17(1), 2007, pp. 2-26.

[52] VERBI Software, MAXQDA 2020, Berlin, Germany, 2019.

[53] Saldaña, J., The Coding Manual for Qualitative Researchers, Sage, 2015.

[54] Wiesche, M., M.C. Jurisch, P.W. Yetton, and H. Krcmar, "Grounded Theory Methodology in Information Systems Research", MIS Quarterly, 41(3), 2017, pp. 685-701.

[55] Belkhodja, O., É. Karuranga, and G.G. Morin, "Reflections on the Client-Consultant Relationship: Challenges and Opportunities in a Context of Organisational Change", Journal of General Management, 37(3), 2012, pp. 1-19.

[56] Stephenson, W., The Study of Behavior; Q-Technique and Its Methodology, University of Chicago Press, 1953.

[57] Brown, S.R., Q Technique and Method: in, W. D. a. L.B. Berry, M. S. (Ed.) New Tools for Social Scientists, Beverly Hills, CA: Sage., 1986.

[58] Sarkar, A., S.C. Wingreen, and P. Cragg, "Organisational IS Resilience: A Pilot Study Using Q-Methodology", in Proceedings of the 24th Australasian Conference on Information Systems, ACIS, Melbourne, 03-05 December. 2013.

[59] Kendall, K.E., J.R. Buffington, and J.E. Kendall, "The Relationship of Organizational Subcultures to DSS User Satisfaction", Human Systems Management, 7(1), 1987, pp. 31-39.

[60] Thomas, D.M. and R.T. Watson, "Q-sorting and MIS Research: A Primer", Communications of the Association for Information Systems, 8, 2002, pp. 141156.

[61] Tractinsky, N. and S.L. Jarvenpaa, "Information Systems Design Decisions in a Global versus Domestic Context", MIS Quarterly, 19(4), 1995, pp. 507-534. 